\title{
EDITORIAL
}

\section{It is time!}

\section{Bhavin Jankharia}

Editor in Chief, Indian Journal of Radiology and Imaging, Bhaveshwar Vihar, 383 Sardar V P Road, Prarthana Samaj, Mumbai - 400004, India. E-mail: editor@ijri.org

Last issue's editorial ${ }^{[1]}$ drew in a lot of comments from examinees and students, but none from the examiners. The 'examination' problem is an issue that is worth discussing in a forum such as this journal and it would be nice if those on the other side were to present their views as well.

Over the last few months, there have been at least two or three very aggrieved letters to the editor regarding the PCPNDT act. ${ }^{[2]}$ We have not accepted them for publication for a variety of reasons, the most important being that the letters would have been out of context at that particular point in time, if not published within the framework of a proper discussion.

It is unfortunate that the sex ratio has further worsened in many states of the country ${ }^{[3]}$ However to make radiologists and the modality of ultrasound scapegoats, only helps divert attention and resources from the real culprits - the prospective parents who ask for and get sex determination done with a view to abort female fetuses, and doctors, mainly gynecologists and obstetricians, who are complicit with their patients in actually performing such abortions. To use management jargon, radiologists are soft targets and ultrasound centers are low-hanging fruit and by focusing on the radiologists and ultrasound centers, we are missing the forest for the trees.

Technology is also outpacing so many of these issues.

A recent issue of the New York Times carried an article on how sex determination today can be performed at seven weeks using blood tests. ${ }^{[4]}$ Another article in the Mumbai Mirror $^{[5]}$ has subsequently highlighted how parents from India are sending blood to the US and flooding those

\begin{tabular}{|l|l|}
\hline \multicolumn{2}{|c|}{ Access this article online } \\
\hline Quick Response Code: & \\
\hline & Website: \\
\hline & www.iji.org \\
\cline { 2 - 3 } & DOI: \\
\hline
\end{tabular}

laboratories with requests for sex determination. Once those results come in, who do you think aids and abets the patients in performing abortions? Not radiologists for sure.

It is time for us to have a reasoned debate on this issue. It is true that there are some black sheep who still perform sex determination using ultrasound. Then there are those who still have not understood the need to have perfect record keeping in their ultrasound centers, with respect to the A and $\mathrm{F}$ forms. It is also a fact that even after following all these rules there have been cases of harassment. Although there are many in the Government who are trying their best to come up with solutions to the problem, there are also those who come with knee-jerk solutions that are then thrust upon doctors and patients.

Emotion is running high among many of us radiologists at this point in time. Meetings see a lot of rhetoric. Officials have their own issues and problems. It is time to try and address these in a more reasoned and balanced manner.

The February 2012 issue will be a special issue on the PCPNDT act and carry articles related to this debate. I would like to invite letters, reasoned articles, and reviews on the subject of the PC-PNDT act and sex determination. We hope to have articles from all the stake holders, including social workers, parents, radiologists, gynecologists, and those in the Government, overseeing the implementation of the Act.

The Indian Journal of Radiology and Imaging hopes and will also ensure that all such articles are free of rhetoric and emotion and based on facts, data, and practical issues.

\section{References}

1. Jankharia B. Why examiners should not forget to be decent human beings. Indian J Radiol Imaging 2011;21:79.

2. Thakker J, Jankharia B. PC-PNDT Act - Part I. Indian J Radiol Imaging 2008;18:3.

3. Gadgil M. Mumbai child sex ratio worsens. Mint 2011;4:3.

4. Belluck P. Is It Boy Or Girl? A Test At 7 Weeks. The New York Times 2011 Aug 10; A1.

5. Shelar J. Parents sign up for blood test to detect foetal sex. Mumbai Mirror 2011 Sept 03;3. 